\title{
Effectiveness of a bundle to prevent unplanned extubation in a pediatric intensive care unit: A multidisciplinary approach
}

\author{
Valéria C Neves, Camila G Ribas, Bruno Miranda, Elessandra Bitencourt, Adriana Koliski, Monica Cat and José Eduardo Carreiro \\ Pediatric Intensive Care Unit, Hospital de Clínicas Complex, Federal University of Paraná (UFPR), Curitiba (PR), Brazil
}

\begin{abstract}
Endotracheal intubation is one of the most common invasive procedures in routine pediatric intensive care. Unplanned extubation occurs when an endotracheal tube is inadvertently removed. To observe and report the incidence of unplanned extubation in children before and after the introduction of a series of measures aimed at controlling and reducing this adverse event in a pediatric intensive care unit. In 2016, a total of 312 patients were hospitalized in the pediatric intensive care unit. Of these, 120 received mechanical ventilation and there were 30 unplanned extubations, corresponding to an annual incidence of 4.24\%. In 2017, the corresponding figures were 301, 163, 42 and 3.4\%. In 2018, after the introduction of measures to control and reduce the number of unplanned extubations, the corresponding figures were 335, 195, 31 and $1.79 \%$. The incidence in 2018 was statistically significantly lower than in 2017 and 2016 (p < 0.01). Systematic control of the incidence of unplanned extubation and the introduction of a bundle of measures led to a significant reduction in this type of extubation in the pediatric intensive care unit.
\end{abstract}

\begin{abstract}
Abbreviations: PICU: Pediatric Intensive Care Unit; MV: Mechanical Ventilation: UPE: Unplanned Extubations; CHC/UFPR: Hospital de Clínicas Complex, Federal University of Paraná; RBR: Brazilian Registry of Clinical Trials; IQC: Internal Quality Group; PDC: Plan Do Check Act; NIV: Non-Invasive Ventilation; SBT: Spontaneous Breathing Trial; ESICM: European Society of Intensive Care Medicine; CPSSQ: Imperial Centre for Patient Safety and Service Quality; NACHRI: National Association of Children's Hospitals \& Related Institutions; NQF: National Quality Forum
\end{abstract}

\section{Introduction}

An intensive care unit is a highly complex unit in a hospital [13]. Correct use of mechanical ventilation (MV) can affect the progress and prognosis of patients hospitalized in a pediatric intensive care unit (PICU) [3-5]. It is therefore fundamental for the safety of critically ill patients to monitor the quality of the services provided $[1,2,4,5]$.

Endotracheal intubation is frequently used in PICUs, and elective extubation should be performed when MV is no longer required [6]. The inadvertent displacement and removal of an endotracheal tube is termed unplanned extubation (UPE) or accidental extubation and constitutes an adverse event [6].

The risks associated with such events are respiratory failure, airway injuries, longer use of MV, increased length of stay in the PICU and longer hospitalization. In addition, there may be an increased risk of hypoxemia, atelectasis and susceptibility to pneumonia associated with MV $[2,4,6,7]$.

Common factors associated with adverse events observed in PICUs are failure to follow protocols and a lack of innovative, adaptive strategies for quality control. The first step in solving a problem is to measure the problem, i.e., to collect data on the processes related to patient care and patient outcomes. Low-cost interventions or even interventions that do not incur additional costs can help to reduce adverse events [1,2].

Once the high risk that UPE poses for the pediatric population is recognized, together with the its impact on duration of MV, length of stay in the PICU, length of hospitalization, morbidity and mortality, it becomes essential to implement effective methods to prevent this adverse event. Many PICUs currently use the incidence of UPE as an indicator of the quality of care [6,7].

This study sought to observe and report the incidence of UPE in children before and after the introduction of a series of measures aimed at controlling and reducing this adverse event in a PICU.

\section{Methods}

The study was a prospective observational study and was carried out in the PICU at the Hospital de Clínicas Complex, Federal University of Paraná (CHC/UFPR) from January 2016 to December 2018. In 2016 and 2017 eight beds were available in the PICU, and in 2018 ten were available. The study was approved by the Institutional Ethics Committee (ref. no. 1.889.488/2017) and registered in the Brazilian Registry of Clinical Trials under ref. no. RBR-6zfy89. A voluntary informed-consent form was signed by the children's parents or the person legally responsible for them.

${ }^{\star}$ Correspondence to: Valéria Cabral Neves, Hospital de Clínicas Complex, 181 General Carneiro Street, Curitiba PR, 80060900, Brazil, E-mail: valeriakabral@ hotmail.com

Key words: critical care, patient safety and quality indicators, pediatric, unplanned extubation

Received: March 13, 2020; Accepted: March 25, 2020; Published: March 28, 2020 
The study population consisted of children of both sexes from 28 days old up to 14 years of age in the PICU at the CHC/UFPR who were intubated and on MV. Children who had a tracheostomy, had undergone planned extubation or needed to have their tubes changed because of a suspected or confirmed obstruction were excluded from the study.

\section{Intervention}

The project to introduce an indicator of UPEs was conceived after an internal quality group (IQG) was set up for the pediatric unit at the CHC/UFPR. The IQG consisted of volunteer staff and staff involved in care provision in the pediatric unit, and the plan-do-check-act (PDCA) method was used to make improvements to the process for prevention of UPEs (Figure 1). This is a tool used in quality management and periodic assessment of work processes ${ }^{8}$ that consists of four sequential phases: plan (P), do (D), check (C) and act (A) $[8,9]$.

In phase P, a UPE indicator was defined, a work group was set up and training was provided on how to monitor events. In phase $\mathrm{D}$, check sheets were created, data for the pediatric unit were collected and all UPE events were recorded and investigated. In addition, monthly reports were drawn up for discussion in meetings with the IQG. In phase $\mathrm{C}$, the data collected were tabulated and analyzed. Finally, in phase $\mathrm{A}$, the data were presented to the multidisciplinary team, a series of UPE-prevention measures were implemented and the PICU team was trained.

Data were collected daily with the aid of a standardized form designed by the researcher responsible for the study. The data recorded on the form included the number of patients admitted to the unit, their epidemiologic characteristics, the number of intubated patients/day on mechanical ventilation and the number of UPEs and their respective causes.

The following formula was used to calculate the incidence of UPEs: number of accidentally extubated patients / number of intubated patients day X 100 [10].

The data were recorded in a spreadsheet (Microsoft Excel $\left.{ }^{\triangleright}\right)$. After the data had been analyzed, a monthly report was issued with the following information: number of intubated patients, number of UPEs, shift (morning, evening or night), time and causes of the UPEs.

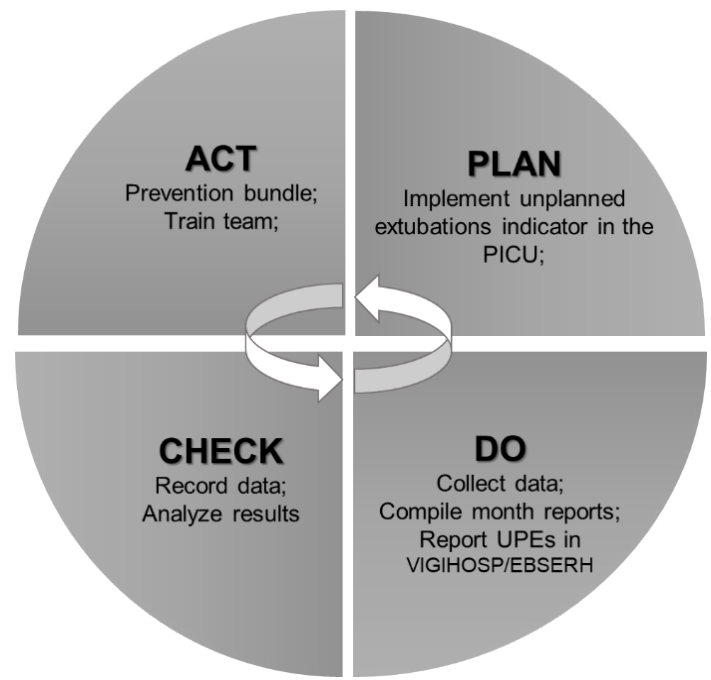

Figure 1. PDCA CYCLE (adapted for the unplanned extubation indicator for the $\mathrm{CHC}$ / UFPR PICU)
Table 1. Bundle for the prevention of unplanned extubations - pediatric intensive care unit, CHC/UFPR, 2017

\section{Bundle to prevent unplanned extubations}

Check regularly that the endotracheal tube is properly fixed.

STANDARDIZE the way that the endotracheal tube is fixed.

CHECK tube position and fixation before handling the patient.

REQUEST that the tube be secured again if it is loose, wet or moving (pay particular attention if the patient is producing excessive secretions or drooling).

RECORD on the high-risk sheet, during each shift, the size of the endotracheal tube and the number on the tube beside the oral fissure or nasal ala.

WHENEVER the position of the tube CHANGES or the fixation IS CHANGED, record this on the control sheet for the endotracheal tube fixation sheet.

Precautions to be taken when the patient is handled by the multidisciplinary team REQUEST assistance from a colleague when performing a procedure for which there is a risk of unplanned extubation.

MONITOR and assist with any procedures performed by non-PICU staff

Steps to be taken when the patient is agitated

USE the scale to assess whether the level of sedation is adequate and inform the medical team in accordance with PICU procedures (Comfort B Scale)

IDENTIFY and adopt containment measures according to the patient's age

ASSESS, inform and record on the patient's medical history the risk of unplanned

extubation on each shift;

Controlling the length of mechanical ventilation

ASSESS whether the use of non-invasive ventilation (NIV) may be appropriate.

ASSESS whether it is appropriate to perform elective extubation and administer the spontaneous breathing trial (SBT) in accordance with PICU procedures.

\section{Recommendations}

INFORM AND PROVIDE GUIDANCE TO the adults responsible for the child on the risks of unplanned extubation and how to prevent it

IDENTIFY individual risk factors

PAY PARTICULAR ATTENTION if the child is less than one year old (high risk of unplanned extubation)

REPORT any unplanned extubation in the VIGIHOSP/EBSERH system

The monthly incidence of UPEs in the PICU was presented to the multidisciplinary team.

All the UPEs were reported by the physiotherapy team with the aid of a specific sheet for this purpose and then entered in a standard program used at the CHC/UFPR (VIGIHOSP/EBSERH) [11].

After the indicator had been monitored for 24 months, an action plan was put in place to implement a bundle of measures aimed at controlling and reducing UPEs in the PICU. The bundle was developed based on an analysis of the reports of adverse events and publicized in the form of a poster (displayed in the unit) and as a booklet for use in theoretical and practical training provided for the whole multidisciplinary team (Table 1).

\section{Statistical analysis}

All the data collected were recorded in a spreadsheet (Microsoft Excel ${ }^{\triangleright}$ ). After they had been checked, the data were exported to Statistica 7.0 (USA) for the statistical analysis. The distributions of the continuous variables were assessed for normality. Variables with a normal distribution were expressed in terms of the mean and standard deviation, and variables with an asymmetric distribution were expressed in terms of the median and $25 \%$ and $75 \%$ percentiles. The Mann-Whitney test was used to estimate the differences between continuous variables with an asymmetric distribution, and the Pearson/ Yates chi-square test was used for categorical variables.

\section{Results}

During the 36-month study period, 478 children were intubated and were on MV. Of these, 103 (21.54\%) were accidentally extubated in the PICU and formed the sample used for the study. Table 2 shows the epidemiologic characteristics of this group of 478 children. 
Of the 103 children who were accidentally extubated, 47 (46.0\%) were female and 56 (54.0\%) male. Median age was 9.0 months, $25 \%$ and $75 \%$ percentiles age were 4.0 and 30.0 months. Orotracheal intubation was used with $96.0 \%$ of the patients, and nasotracheal intubation with 4.0\%. Eighty-seven patients (84\%) used tubes without a cuff, and 16 (16\%) used tubes with a cuff. Median duration of MV was 10.0 days, $25 \%$ and $75 \%$ percentiles duration were 5.0 and 18.0 days and the median day of MV on which UPEs occurred was day 3, and the earliest and latest days were day 2 and day 9 (Table 2).

The characteristics of the UPEs are shown in table 3 , and the causes of the UPEs included in the notifications are shown in table 4.

In 2016, a total of 312 patients were admitted to the PICU, of whom 120 (38.4\%) were treated with MV. The PICU had an occupancy of

Table 2. Epidemiologic characteristics of the patient sample from the pediatric intensive care unit, CHC/UFPR - 2016, 2017, 2018.

\begin{tabular}{|c|c|c|c|}
\hline Characteristic & $\begin{array}{l}\text { UPE group } \\
(\mathrm{n}=103)\end{array}$ & $\begin{array}{c}\text { Group without } \\
\text { UPEs } \\
(\mathrm{n}=375)\end{array}$ & $p$ \\
\hline Sex M/F (n) & $56 / 47$ & $173 / 202$ & $0.17^{1}$ \\
\hline Age $^{1}$ (months) & $9.0(4-30)$ & $29.0(9-96)$ & $<0.001^{2}$ \\
\hline Weight $^{1}(\mathrm{~kg})$ & $8.5(4.6-13)$ & $13.0(6.4-20)$ & $<0.001^{2}$ \\
\hline \multicolumn{4}{|l|}{ Tube } \\
\hline Orotracheal & $99(96.1 \%)$ & $341(90.1 \%)$ & $0.12^{1}$ \\
\hline Nasotracheal & $4(3.9 \%)$ & $34(9.1 \%)$ & \\
\hline With cuff & $16(15.5 \%)$ & $157(41.9 \%)$ & $<0.001^{1}$ \\
\hline Without cuff & $87(84.5 \%)$ & $218(58.1 \%)$ & \\
\hline UPE day* & $5.0(2.0-9.0)$ & - & \\
\hline $\begin{array}{l}\text { Duration of mechanical } \\
\text { ventilation }^{1}\end{array}$ & $10.0(5-18)$ & $7.0(4-11)$ & $<0.001^{2}$ \\
\hline Tracheostomy required & $11.0(10.7 \%)$ & $12(3.2 \%)$ & $<0.01^{1}$ \\
\hline \multicolumn{4}{|l|}{ Outcome } \\
\hline Discharge & $96.0(93.2 \%)$ & $341(90.9 \%)$ & $0.59^{1}$ \\
\hline Death & $7.0(6.8 \%)$ & $34(9.1 \%)$ & \\
\hline \multicolumn{4}{|c|}{$\begin{array}{l}\text { SOURCE: The author (2019). } \\
\text { NB: }{ }^{1} \text { Pearson/Yates chi-squared test, }{ }^{2} \text { Mann-Whitney test. Values expressed as median } \\
\text { and } 25 \% \text { and } 75 \% \text { percentiles and the difference between the groups in the Mann- } \\
\text { Whitney test. F: female; M: male. UPE: unplanned extubation. } * \text { UPE day: no. of days on } \\
\text { mechanical ventilation when unplanned extubation occurred. }\end{array}$} \\
\hline
\end{tabular}

Table 3. Characteristics of unplanned extubations in the patient sample from the pediatric intensive care unit, CHC/UFPR - 2016, 2017, 2018.

\begin{tabular}{|c|c|c|c|c|}
\hline Characteristic & $\begin{array}{c}2016 \\
(n=30)\end{array}$ & $\begin{array}{c}2017 \\
(n=42)\end{array}$ & $\begin{array}{c}2018 \\
(n=31)\end{array}$ & $p$ \\
\hline \multicolumn{5}{|l|}{ Ventilation mode } \\
\hline $\mathrm{A} / \mathrm{C}$ & $15(50.0 \%)$ & $25(59.5 \%)$ & $19(61.3 \%)$ & \multirow{3}{*}{0.89} \\
\hline SIMV+PSV & $15(50.0 \%)$ & $14(33.3 \%)$ & $9(29.0 \%)$ & \\
\hline PSV & $0(0.0 \%)$ & $3(7.1 \%)$ & $3(9.7 \%)$ & \\
\hline \multicolumn{5}{|l|}{ Sedation } \\
\hline Yes & $25(83.3 \%)$ & $39(92.9 \%)$ & $20(64.5 \%)$ & \multirow[b]{2}{*}{$<0.01$} \\
\hline No & $5(16.7 \%)$ & $3(7.1 \%)$ & $11(35.5 \%)$ & \\
\hline \multicolumn{5}{|l|}{ Age } \\
\hline$<12$ months & $18(60.0 \%)$ & $27(64.3 \%)$ & $14(45.2 \%)$ & \multirow[b]{2}{*}{0.24} \\
\hline$>12$ months & $12(40.0 \%)$ & $15(35.7 \%)$ & $17(54.8 \%)$ & \\
\hline \multicolumn{5}{|l|}{ Shift } \\
\hline Morning & $8(26.7 \%)$ & $8(19.0 \%)$ & $8(25.8 \%)$ & \multirow{3}{*}{0.18} \\
\hline Afternoon & $12(40.0 \%)$ & $10(23.8 \%)$ & $13(41.9 \%)$ & \\
\hline Night & $10(33.3 \%)$ & $24(57.1 \%)$ & $10(32.3 \%)$ & \\
\hline \multicolumn{5}{|l|}{ Weekend } \\
\hline Yes & $7(23.3 \%)$ & $17(40.5 \%)$ & $10(32.3 \%)$ & \multirow{2}{*}{0.31} \\
\hline No & $23(76.7 \%)$ & $25(59.5 \%)$ & $21(67.7 \%)$ & \\
\hline \multicolumn{5}{|l|}{ Reintubation } \\
\hline Yes & $22(73.3 \%)$ & $33(78.6 \%)$ & $18(58.1 \%)$ & \multirow{2}{*}{0.15} \\
\hline No & $8(26.7 \%)$ & $9(21.4 \%)$ & $13(41.9 \%)$ & \\
\hline
\end{tabular}

Table 4. Causes of unplanned extubations in the patient sample from the pediatric intensive care unit, CHC/UFPR - 2016, 2017, 2018

\begin{tabular}{|c|c|c|c|c|}
\hline Cause of UPE & $\begin{array}{l}2016 \\
(n=30)\end{array}$ & $\begin{array}{l}2017 \\
(n=42)\end{array}$ & $\begin{array}{l}2018 \\
(n=31)\end{array}$ & $p$ \\
\hline \multicolumn{5}{|c|}{ Patient handling by team } \\
\hline $\begin{array}{l}\text { Yes } \\
\text { No }\end{array}$ & $\begin{array}{l}19(63.3 \%) \\
11(36.7 \%)\end{array}$ & $\begin{array}{l}23(54.8 \%) \\
19(45.2 \%)\end{array}$ & $\begin{array}{l}14(45.2 \%) \\
17(54.8 \%)\end{array}$ & 0.36 \\
\hline \multicolumn{5}{|c|}{ Insufficient sedation } \\
\hline $\begin{array}{l}\text { Yes } \\
\text { No }\end{array}$ & $\begin{array}{l}11(36.7 \%) \\
19(63.3 \%)\end{array}$ & $\begin{array}{l}32(76.2 \%) \\
10(23.8 \%)\end{array}$ & $\begin{array}{l}17(54.8 \%) \\
14(45.2 \%)\end{array}$ & $<0.001$ \\
\hline \multicolumn{5}{|c|}{ Psychomotor agitation } \\
\hline $\begin{array}{l}\text { Yes } \\
\text { No }\end{array}$ & $\begin{array}{l}17(56.7 \%) \\
13(43.3 \%)\end{array}$ & $\begin{array}{l}29(69.0 \%) \\
13(31.0 \%)\end{array}$ & $\begin{array}{l}19(61.3 \%) \\
12(38.7 \%)\end{array}$ & 0.54 \\
\hline \multicolumn{5}{|c|}{ Fixation of the tube } \\
\hline $\begin{array}{l}\text { Effective } \\
\text { Ineffective }\end{array}$ & $\begin{array}{l}20(66.7 \%) \\
10(33.3 \%)\end{array}$ & $\begin{array}{l}25(59.5 \%) \\
17(40.5 \%)\end{array}$ & $\begin{array}{l}11(35.5 \%) \\
20(64.5 \%)\end{array}$ & 0.03 \\
\hline \multicolumn{5}{|c|}{ Position of the tube } \\
\hline $\begin{array}{l}\text { Effective } \\
\text { Ineffective }\end{array}$ & $\begin{array}{c}22(73.3 \%) \\
8(26.7 \%)\end{array}$ & $\begin{array}{c}33(78.6 \%) \\
9(21.4 \%)\end{array}$ & $\begin{array}{l}20(64.5 \%) \\
11(35.4 \%)\end{array}$ & 0.40 \\
\hline
\end{tabular}

74.0\%. The number of intubated-patient days was 877 . There were 30 UPEs, corresponding to an annual incidence of UPEs of $4.24 \%$.

In 2017, a total of 301 patients were admitted to the PICU, of whom 163 (54.1\%) required MV. Occupancy for the unit was $94.0 \%$, the number of intubated patient days was 1176 and there were 42 UPEs, corresponding to an annual incidence of $3.57 \%$.

In 2018, a total of 335 patients were admitted to the PICU, of whom 195 (58.2\%) were treated with MV. Occupancy for the unit was $84.0 \%$, the number of intubated patient days was 1728 and there were 31 UPEs, corresponding to an annual incidence of $1.79 \%$.

Figure 2 shows the monthly incidence of UPEs.

The total number of intubated patient days for the study period was 3.781, and the mean UPE incidence rates in 2016, 2017 and 2018 were $4.24 \%, 3.48 \%$ and $1.79 \%$, respectively. The incidence in 2018 was statistically significantly lower than in 2017 and 2016 (p < 0.01).

\section{Discussion}

Of the 103 children who were accidentally extubated, 47 were female, 56 male and median age was 9.0 months. According to the literature, the mean age of pediatric patients on $\mathrm{MV}$ is 12 months $[3,12]$. In various studies of the population in PICUs, male patients predominated [3,13-15].

The median day of MV on which UPEs occurred was day 3, and the earliest and latest days were day 2 and day 9. Median duration of MV was 10 days and $25 \%$ and $75 \%$ percentiles duration were 5 and 18 days, higher than the corresponding figure (7 days) for children who were not accidentally extubated. Pediatric studies report an association between UPE and longer use of MV, increased length of stay in hospital and increased hospital costs [16-20]. Hight incidence of tracheostomies is significant in patients who had accidental extubation, probably due to reintubation trauma and increased length of stay on MV.

Studies frequently describe weaning off $\mathrm{MV}$ as a potential risk factor for UPE because the withdrawal of sedation causes psychomotor agitation. However, in the present study the extubations occurred during the first days of $\mathrm{MV}$, when the patients were on assist-control MV (57.0\%) and receiving sedatives (82.0\%). This would suggest that the UPEs in these patients occurred when they were being handled by the team but also that sedation was insufficient, leading to excessive agitation during patient handling. 


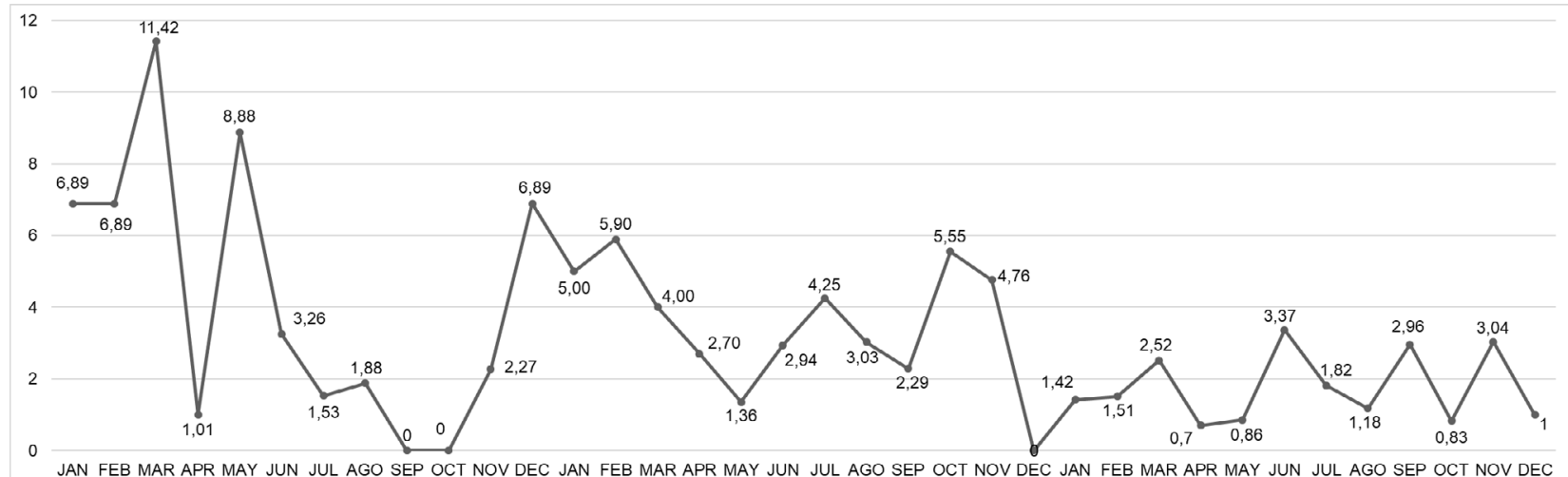

Figure 2. Incidence of unplanned extubations in the pediatric intensive care unit at CHC/UFPR, 2016-2018

A possible explanation for the high reintubation rate $(71 \%)$ is that most of the patients were on assist-control MV and were being administered sedatives continuously. Various studies have reported high reintubation rates (from $36.0 \%$ to $73.0 \%$ ), the main causes of which are related to hypoxemia, excessive secretion and hypoventilation [16,19,21-24]. The use of noninvasive ventilation as an important measure to avoid the need for reintubation is currently the subject of discussion [25].

Menon et al., (2015) and Tripathi et al., (2015) found that UPE was more common among patients under 12 months of age, corroborating the findings of the present study. One factor associated with UPE in pediatric patients is the size of the child, as infants have a smaller body surface on which the tube can be secured. Furthermore, these patients frequently present with excessive secretions and drooling [26,27].

Of the three shifts, the night shift had the most UPEs (43.0\%); however, when the two daytime shifts (morning - 6 hours and afternoon - 6 hours) were considered together, these accounted for the majority of the UPEs (57\%). Of particular note is the higher incidence of UPEs 35 (34\%) between 13:00 and 19:00. In another study with similar findings, the frequency of UPEs was greater during the first hours of the morning shift, when patient care was intensified [27].

Of the 103 UPEs, one third occurred during weekends. The greater number of UPEs during the night shift and weekends may be a consequence of the smaller number of staff from the multidisciplinary team on duty [27].

Although an editorial review of fourteen studies on risk factors for UPE in adult, pediatric and newborn patients failed to find a risk factor related to shift time, factors such as team members' experience, patient complexity and excessive team/career workload, for which there is a lack of information, may explain the differences in the results [16,27].

When a UPE was reported, could attribute it to more than one cause. The main causes observed in the present study were patient handling by the team $(54.0 \%)$, insufficient sedation (58.0\%), psychomotor agitation (63.0\%), incorrectly endotracheal tubes fixation (46.0\%) and incorrectly positioned endotracheal tubes $(27.0 \%)$. There is a consensus in the literature that insufficient sedation, an fixation and an incorrect positioning of the endotracheal tube and excessive secretions are the most common causes of UPE and are a result of a lack of standardized procedures for endotracheal intubation [16,21,26,28-30].

The PDCA method is a useful tool for solving complex problems such as UPE and can be used to test multiple interventions and solutions for such problems. It is based on interactive cycles, the results of which are used in turn to plan new interventions and cycles. The flexibility afforded by these cycles allows any harm to the patient to be minimized, and the effectiveness of the model has been shown in various studies on care quality $[8,16-18,30]$.

As UPEs are a quality indicator that involves multifactorial causes, it is reasonable to expect a bundle-based approach to allow various probable causes to be treated at the same time [16]. Interventions based on a multidisciplinary approach have been found to reduce UPE rates, but the complex interaction of the risk factors involved has yet to be identified. It is crucial to identify patients at potential risk and develop effective low-cost, easily implemented interventions. This way, the quality of care provided for intubated children can be improved.

The bundle of measures to control and reduce UPEs in the PICU in this study was based on the reported and investigated causes of UPEs and sought to standardize actions that would reduce exposure to the main risk factors observed. The bundle was introduced during training for the whole multidisciplinary PICU team and was presented in a discussion forum used by the hospital IQG.

The elements in the bundle are measures that must be followed systematically. After the bundle had been implemented and the team had been trained, there was an increase in the number of intubated patient days and a reduction in the incidence of UPEs in the PICU.

In the first decade of this century, organizations such as the European Society of Intensive Care Medicine (ESICM), the Imperial Centre for Patient Safety and Service Quality (CPSSQ) and the Critical Care Secretariat (Canada) included UPEs as an indicator of intensivecare quality and safety. However, the Agency for Healthcare Research and Quality and the National Association of Children's Hospitals and Related Institutions (NACHRI), which are endorsed by the National Quality Forum(NQF), do not consider UPEs an indicator of quality in pediatric care $[16,31,32]$. There is thus a lack of consensus among these organizations as to whether UPEs can be considered an indicator of quality and safety in an ICU.

Despite this lack of consensus, some researchers have shown an interest in making control of UPEs an indicator of quality and safety in pediatric intensive care units. Recent studies on the incidence of UPEs and associated risk factors, as well as results, can help to improve pediatric clinical practice and extubation programs $[16,19,26,27]$.

The fact that the present study did not compare the incidence of UPEs with the number of electively extubated patients together with 
the small number of beds in the PICU can be considered limitations of the study. Further research is under way by our group with a view to developing a sensitive tool to prevent UPEs in the pediatric population in intensive care units.

\section{Conclusions}

In conclusion, systematic control of the incidence of UPEs and the introduction of a bundle of measures led to a significant reduction in these adverse events in the PICU in this study. We believe that controlling this situation can contribute to improving safety and quality of care for intubated patients.

\section{References}

1. Kashyap R, Hache-Marliere M, Gavrilovic S, Gajic O (2015) Improving outcomes for the critically ill in developing countries: what is next? Rev Bras Ter Intensiva 27: 312314. [Crossref]

2. Fernandes HS, Júnior SAP, Filho RC (2010) Qualidade em terapia intensiva. Rev Bras Clin Med 8: 37-45.

3. Kneyber MCJ, Luca D, Calderini E (2017) Recomendations for mechanical ventilation of critically ill children from the paediatric mechanical ventilation consensus conference (PEMVECC). Intensive Care Med 43: 1764-1780.

4. Alves MVMFF, Bissiguini PO, Nitsche MJT (2014) Profile of patients admitted in a pediatric intensive care unit of a hospital school in the countryside of São Paulo. Cienc Cuid Saude 13: 294-301.

5. Cheifetz IM (2013) Advances in monitoring and management of pediatric acute lung injury. Pediatr Clin N Am 60: 621-639. [Crossref]

6. Rachman BR, Watson R, Woods N, Mink RB (2009) Reducing unplanned extubations in a pediatric intensive care unit: a systematic approach. Int J Pediatr 2009:1-5. [Crossref]

7. Razavi SS, Nejad RA, Mohajerani AS, Talebian M (2013) Risk fators of unplanned extubation in pediatric intensive care unit. Tanaffos 12: 11-16.

8. Taylor MJ, McNicholas C, Nicolay C, Darzi A, Bell D, et al. (2014) Systematic review of the application of the plan-do-study-act method to improve quality in healthcare. BMJ Qual Saf 23: 290-298. [Crossref]

9. Souza PCP; Knibel MF (2014) Série Clínicas de MedicinaIntensivaBrasileira. Gestão, Qualidade e Segurançaem UTI, Ano 19 - Vol. 21. São Paulo Ed. Atheneu p.17,21,101-134.

10. CDC, Ncezid, DHQP (2019) National Healthcare Safety Network (NHSN) Patient Safety Component Manual [Internet]. Disponívelem: https://www.cdc.gov/nhsn/pdfs/ hps-manual/vaccination/hps-flu-vaccine-protocol.pdf $>$. Acess 22 de abril de 2019.

11. VIGHIOSP/EBSERH. Disponívelem: $<$ http://www2.ebserh.gov.br/web/sig /vigihosp/ manual-dousuario\#aba_classificar_incidente_sobre_outras_notificac oes $>$. Acessem: 20 de fevereiro de 2019 .

12. Farias JA, Frutos F, Esteban A, Flores JC, Retta A, et al. (2004) What is the daily practice of mechanical ventilation in pediatric intensive care units? A multicenter study. Intensive Care Med 30: 918-925. [Crossref]

13. Lanetzki, C.S, Oliveira CAC, Bass LM et al. (2012) O perfilepidemiológico do centro de terapiaintensivapediátrico do Hospital Israelita Albert Einstein. Einstein. 10: 16-21.

14. Einloft PR, Garcia PC, Piva JP, et al. (2002) Perfilepidemiológico de dezesseisanos de umaunidade de terapiaintensivapediátrica. Rev Saúde Pública 36: 728-733.
15. Batista NOW, Coelho MCR, Trugilho SM (2015) Perfilclínico-epidemiológico de pacientesinternadosemunidade de cuidadosintensivospediátricos. J Hum Growth Dev 250: $182-193$

16. Silva PSL, Farah D, Fonseca MCM (2017) Revisiting unplanned extubation in the pediatric intensive care unit: What's new? Heart Lung 46: 444-451. [Crossref]

17. Sadowski R, Dechert RE, Bandy KP (2004) Continuous quality improvement: reducing unplanned extubations in a pediatric intensive care unit. Pediatrics 114: 628-632. [Crossref]

18. Silva PS, de Aguiar VE, Neto HM, de Carvalho WB (2008) Unplanned extubation in apaediatric intensive care unit: impact of a quality improvement programme. Anaesthesia 63: 1209-1216. [Crossref]

19. Fitzgerald RK, Davis AT, Hanson SJ (2015) Multicenter analysis of the factors associated with unplanned extubation in the PICU. Pediatr Crit Care Med 16: 217 223. [Crossref]

20. Roddy DJ, Spaeder MC, Pastor W, Stockwell DC, Klugman D (2015) Klugman. Unplanned extubations in children: impact in hospital cost and lenght of stay. Pediatr Crit Care Med 16: 572 -575. [Crossref]

21. Tripathi S, Nunez DJ, Katyal C, Ushay HM (2015) Plan to have No unplanned: a collaborative, hospital-based quality-improvement project to reduce the rate of unplanned extubations in the pediatric ICU. Respir Care 60: 1105-1112. [Crossref]

22. Kanthimathinathan HK, Durward A, Nyman A, Murdoch IA, Tibby SM (2015) Unplanned extubation in a paediatric intensive care unit: prospective cohort study. Intensive Care Med 41: 1299-1306. [Crossref]

23. Meregalli CN, Jorro Baron FA, D’Alessandro MA, Danzi EP, Debaisi GE (2013) Impact of a quality improvement intervention on the incidence of unplanned extubations in a Pediatric Intensive Care Unit. Arch Argent Pediatr 111: 391-397. [Crossref]

24. Menon K, Dundon B, Twolan BL, AlShammari S (2015) Approach to unplanned extubations in a pediatric intensive care unit. Can J Crit Care Nurs 26: 25-29. [Crossref]

25. Chia PL, Santos DR, Tan TC, Leong C, Foo D (2013) Clinical quality improvement: eliminating unplanned extubation in the CCU. Int J Health Care Qual Assur 26: 642652. [Crossref]

26. Razavi SS, Nejad RA (2013) Risk Factors of Unplanned Extubation in Pediatric Intensive Care Unit. Tanaffos 12: 11-16. [Crossref]

27. Mehta NM, Sharma S, Laussen PC (2015) Unplanned extubation: securing the tool of our trade. Intensive Care Med 41: 1983-1985. [Crossref]

28. Kaufman J, Rannie M, Kahn MG, Vitaska M, Wathen B, et al. (2012) An interdisciplinary initiative to reduce unplanned extubations in pediatric critical care units. Pediatrics 129: 1594-1600. [Crossref]

29. Rachman BR, Mink RB (2013) A prospective observational quality improvement study of the sustained effects of a program to reduce unplanned extubations in a pediatric intensive care unit. Paediatr Anaesth 23: 614-620. [Crossref]

30. Abdwani R, Willians CB, Dunn C (2018) Incidence, outcomes and outcome prediction of unplanned extubation in critically ill children: An 11 year experience. J Crit Care 44: 368-375. [Crossref]

31. Rhodes A, Moreno RP, Azoulay E (2012) Prospectively defined indicators to improve the safety and quality of care for critically ill patients: a report from the Task Force on Safety and Quality of the European Society of Intensive Care Medicine (ESICM). Intensive Care Med 38: 598-605. [Crossref]

32. Tsang C, Palmer W, Aylin P (2008) National Institute for Health Research: Patient Safety Indicators: A Systematic Review of the Literature 2008. Available from: URL https:// www1.imperial.ac.uk/resources/0D60DED9-022F-4F8D-BBE5-48D35857CF94/. Accessed March 9, 2017.

Copyright: (C2020 Neves V. This is an open-access article distributed under the terms of the Creative Commons Attribution License, which permits unrestricted use, distribution, and reproduction in any medium, provided the original author and source are credited. 